\title{
TRANSPIRATION DF TREE SPECIES IN DIFFERENT VERTICAL LAYERS OF A KANDYAN FOREST GARDEN
}

\author{
${ }^{1}$ WAJM De Costa, ${ }^{2}$ SP Amaratunga and ${ }^{2}$ RS Udumullage \\ ${ }^{1}$ Department o grop Science, Faculty of Agriculture, \\ University of Peradeniya, Peradeniya \\ ${ }^{2}$ Department of Agric.lture Engineering; Faculty of Agriculture, \\ Universiiy of Peradeniya, Peradeniya
}

Water use of a forest ecosystem is in important determinant of the water balance of a whole watershed. Kandyan Forest Gardens (KFGs) contain a mixture of different tree species. The different tree species are of different sizes and are arranged into distinct vertical canopy layers. The total water use of the KFG is dit trmined by the transpiration rates of individual trees, which form these different vertical layers.

The study was conducted in a KGF at Pilapitiya, Pilimathalawa in the Mid-Country Wet Zone $\left(\mathrm{WM}_{3}\right)$ during the period from Ma $\mathrm{C}$ to July 2001 . A vegetation survey showed that there were 56 tree species in this KFG. Out of these, three tree species representing three vertical canopy layers were selected for continuous measurement of transpiration. These were Jak (Artocarpus heterophyllus), toona (Toona ciliata) and Mahogany (Swietenia macrophylla) which represented upper, middle and lower canopy layers respectively. Transpiration of all trees was measured as the sap flow in their trunks using two thermal methods. In jak (DBH $=40.5 \mathrm{~cm}$ ) and toona $(\mathrm{DBH}=9 \mathrm{~cm})$, which had larger trur $\mathrm{k} ;$, sap flow was measured using thermal dissipation probes. In mahogany, which had a smaller tunk $(\mathrm{DBH}=3 \mathrm{~cm}$ ), sap flow was measure using a dynagage. Solar radiation incident on the respective tree canopies were measured using tube solarimeters. Relative humidity in the open anc inside the KFG was measured by two solid state humidity sensors. Soil moisture content at th 6 s soil depths $(30,60$ and $120 \mathrm{~cm})$ was measured using theta probes. All measurements were done continuously at 30 second time intervals using a data logger. The data were averaged every 5 minutes and stored in the logger.

Detailed continuous measurements taken during a 72 -hour period (i.e. from 0000 hours on 23.06.2001 to 2400 hours 25.06.2001) were analysed. All three-tree species showed similar diurnal variation patterns in their ssp flow rates with maximum rates occurring between 1300 and 1400 hours. Sap flow rate of jais was significantly greater than those of toona and mahogany, which did not differ significantly. However, the velocity of sap flow was highest in the smallest tree, i.e. mahogany, and decreased with increasing sap wood cross-sectional area. The daily transpiration rates of toona and mahc gany ranged from $19 \%$ to $27 \%$. The incident solar radiation was highest on the upper canopy tree (i.e. jak). Both the middle canopy (toona) and lower canopy (mahogany) trees received similar levels of radiation because of the incomplete upper canopy cover in the KFG. There was a clear linear relationship between daily transpiration of all tree species and the solar radiation levels received by the respective trees. This relationship can be used to predict the daily water use of a given tree when there is no significant soil water deficit.

The relative humidity $(\mathrm{RH})$ under both open conditions and within the KFG showed a similar variation pattern. However, $\mathrm{RH}$ within the KFG was slightly higher than that in the open. Transpiration rates of all tree specics had negative linear relationships with the respective RH values experienced by them. 